\title{
Titanocene anticancer complexes and their binding mode of action to human serum albumin: a computational study
}

Article

Accepted Version

Sarsam, S. W., Nutt, D. R., Strohfeldt, K. and Watson, K. A. (2011) Titanocene anticancer complexes and their binding mode of action to human serum albumin: a computational study. Metallomics, 3 (2). pp. 152-161. ISSN 1756-5901 doi: https://doi.org/10.1039/c0mt00041h Available at https://centaur.reading.ac.uk/18302/

It is advisable to refer to the publisher's version if you intend to cite from the work. See Guidance on citing.

Published version at: http://dx.doi.org/10.1039/c0mt0004 1h

To link to this article DOI: http://dx.doi.org/10.1039/c0mt00041h

Publisher: RSC Publishing

All outputs in CentAUR are protected by Intellectual Property Rights law, including copyright law. Copyright and IPR is retained by the creators or other copyright holders. Terms and conditions for use of this material are defined in the End User Agreement.

www.reading.ac.uk/centaur 
Central Archive at the University of Reading

Reading's research outputs online 


\section{Titanocene anticancer complexes and their binding mode of action to}

\section{human serum albumin: A computational study}

Susan Sarsam ${ }^{\mathrm{a}}$, David Nutt ${ }^{\mathrm{b}}$, Katja Strohfeldt $^{\mathrm{a}}$ and Kimberly A Watson ${ }^{\mathrm{c}, *}$

$s$

${ }^{\mathrm{a}}$ School of Pharmacy, ${ }^{\mathrm{b}}$ School of Chemistry and ${ }^{\mathrm{c}}$ School of Biological Sciences, University of Reading, Whiteknights

Campus, Reading, UK, RG6 6AS

${ }_{10}$ Key words: titanocene, cancer, human serum albumin, docking

15

*Correspondence

Dr. Kimberly A. Watson

${ }_{20}$ School of Biological Sciences

Harborne Building

Whiteknights Campus

University of Reading

Reading, Berkshire, UK

${ }_{25}$ RG6 6AS

Email: k.a.watson@ reading.ac.uk

Tel.: +44 (0)118 3786640 
CREATED USING THE RSC ARTICLE TEMPLATE (VER. 3.0) - SEE WWW.RSC.ORG/ELECTRONICFILES FOR DETAILS

\begin{abstract}
Due to the pivotal role played by human serum albumin (HSA) in the transport and cytotoxicity of titanocene complexes, a docking study has been performed on a selected set of titanocene complexes to help clarify the potential mode of action of these titanocenes upon binding HSA. Analysis of the ${ }_{5}$ docking results has revealed potential binding modes for these titanocenes at the known drug binding sites in HSA. Additionally, a new alternative binding site for these titanocenes has been postulated.
\end{abstract}




\section{Introduction}

Metal-based antitumour agents have gained significant interest since the discovery of the antitumour activities of cis-platin (Fig. 1a). ${ }^{1}$ However, due to toxic side effects of this chemotherapeutic agent ${ }^{2,3}$ such as myelotoxicity and nephrotoxicity, in addition to the high risk of developing tumour resistances, ${ }_{5}$ research has progressed to other metal-based chemotherapeutic agents such as metallocene dihalides; $\mathrm{Cp}_{2} \mathrm{MX}_{2} .{ }^{4}$ Metallocene dihalides, containing a variety of transition metals $(\mathrm{M}=\mathrm{Ti}, \mathrm{V}, \mathrm{Nb}, \mathrm{Mo})$, showed remarkable antitumour activity when tested in-vivo using simple animal models. ${ }^{4}$ Among all the metallocenes tested, titanocene dichloride $\mathrm{Cp}_{2} \mathrm{TiCl}_{2}$ (Fig. 1b) was initially found to exhibit the most impressive chemotherapeutic activity against colon, lung and breast cancers. ${ }^{3}$ Titanocene dichloride ${ }_{10}$ entered clinical trials in 1993, but results from phase II clinical trials in patients with advanced renal cell carcinoma and breast metastatic carcinoma were not sufficiently promising ${ }^{5,6}$ and further clinical trials were abandoned. In general, albumin is important to cancer cells as a nutrient and energy supply in order to facilitate their rapid growth. An anti-cancer drug bound to albumin is of significant advantage as this facilitates the uptake across the endothelial cell wall of blood vessels of tumours in ${ }_{15}$ an albumin receptor-mediated transport pathway. ${ }^{7}$

In the last two decades, there has been a growing interest towards the development of new substituted titanocene dichloride derivatives (Fig. 2). McGowan and co-workers synthesized a number of ionic titanocenes which have improved water solubility and were found to be highly effective against ${ }_{20}$ ovarian cancers. ${ }^{8-10}$ Another series of water soluble titanocene dichloride complexes was synthesized by Baird et al. and found to be effective against lung and ovarian cancers. ${ }^{11}$ On the other hand, the current efforts by Tacke et al. have focused on the development of substituted titanocene complexes starting from substituted fulvenes. This has resulted in the synthesis of substituted titanocenes that exhibit remarkable antitumour activity against kidney carcinoma LLC-PK cell line, with IC $_{50}$ values ${ }_{25}$ reaching $5.4 \mu \mathrm{M}$ range. ${ }^{12-35}$ Synthetic efforts are ongoing and aimed at developing new titanocene complexes exhibiting potent cytotoxic activity along with reduced side effects and non-cross resistance.

While the exact mechanism of action of titanocene dichloride complexes is still poorly understood, ${ }_{30}$ several investigations have shown that both transferrin and albumin could serve as possible routes for the delivery of titanocenes to cancer cells ${ }^{36-39}$, whereas DNA is believed to be the main cellular target for these titanocene complexes. ${ }^{40-42}$ Tacke and co-workers have confirmed the crucial role played by 
binding to serum albumins in the cytotoxicity of titanocene complexes, since cancer cells are known to be leaky for albumin due to enhanced vascular permeability and retention effects. ${ }^{7}$ Research has shown for example that Titanocene $\mathrm{Y}$ has only a cytotoxic effect in the presence of serum albumin when tested on the oestrogen-depending breast cancer cell line MCF-7. ${ }^{7}$ Furthermore, evidence for the s binding mode of Titanocene $\mathrm{Y}$ was presented from a simple molecular docking experiment. Using the crystal structure of an albumin-fatty acid complex, a similarly sized fatty acid molecule was removed in order to create a hypothetical binding pocket for Titanocene Y. Results showed that a complementary-shaped binding site was apparent and the titanocene could be stabilized by hydrogen bonds involving the $p$-methoxy group of the sandwich complex and the $\mathrm{CH}_{2} \mathrm{OH}$ group of a serine (Ser) ${ }_{10}$ residue from the protein. $^{7}$

Crystallographic determination of the 3-D structure of human serum albumin (HSA) has shown that HSA comprises three homologous $\alpha$-helical domains named I, II and III with each domain subdivided into two sub-domains A and B. ${ }^{43,44}$ A crystallographic study by Curry et al. has identified a total of 7 ${ }_{15}$ binding sites that are occupied by medium and long chain fatty acids, with additional sites for medium chain fatty acids yielding a total of 11 possible binding sites (Fig. 3). ${ }^{45}$ Extensive studies on drugbinding sites in HSA has resulted in the accepted proposal of two principal primary drug-binding sites, named drug-site I and II located in the sub-domains IIA and IIIA, respectively (Fig. 3). ${ }^{46}$

${ }_{20}$ Molecular docking studies are an important tool in providing crucial understanding of the possible binding mode of drugs and as a result they can be used to identify potential lead compounds. Examples include a Surflex-Dock study by Lee et al., which was carried out in order to elucidate possible binding modes of certain cytotoxic compounds (benz[b]oxepines and 12oxobenzo[c]phenanthridinones) as topoisomerase inhibitors. ${ }^{47}$ In addition, Montembault et al. reported ${ }_{25}$ the synthesis of antiviral drugs as potential Tat HIV-1 inhibitors, called TDS compounds. ${ }^{48}$ These TDS molecules were designed with support from docking experiments. ${ }^{48}$ As a general principle, molecular docking studies typically screen datasets of small molecules by orienting and scoring the molecules when bound to the active site of a protein. Top ranked molecules may become lead compounds for drug development and optimization. Indeed, docking studies play an important role in rational drug ${ }_{30}$ design and discovery. 
To date, no systematic molecular docking studies have been reported for the potential drug class titanocenes. This paper reports, for the first time, a systematic receptor-based docking approach for a database of 16 titanocene derivatives exhibiting a range of structural and biological activity in order to shed light on understanding the mode of action of these titanium-based anticancer drugs against HSA.

5

\section{Materials and Methods}

The described study compromised 16 titanocene derivatives taken from the literature ${ }^{12}$ (see Table 1), which constituted the dataset. The compounds were selected based on the following criteria:

1. All selected compounds are tested for their cytotoxic activity on the same cancer cell line in order to enable a direct comparison of their efficacy.

2. The selected compounds are diverse in both structure and antitumour activity, expressed as $\mathrm{IC}_{50}$, allowing structural features to be correlated to cytotoxic activity.

3. Only achiral compounds were selected for this study in order to avoid complication connected to the presence of stereoisomers. Up to now it has not been possible to separate the stereoisomers of chiral substituted-titanocenes and as a result it is not possible to assign $\mathrm{IC}_{50}$ values to individual stereoisomers. Such mixtures complicate the structure-activity relationship.

Furthermore, the titanocenes chosen were representative of different classes of substituted titanocene ${ }_{20}$ dichlorides, namely benzyl-substituted titanocenes 1a-d and 2a-c, achiral: bis-dimethylaminofunctionalized titanocenes 3a-c, diheteroaryl-substituted titanocenes 4a-c and diaryl-substituted titanocenes 5a-c. Moreover, these titanocenes showed a wide range of cytotoxic activity and all were tested against the same (LLC-PK) cell line using an MTT-based assay, as described in the literature ${ }^{12}$.

${ }_{25}$ The three-dimensional structure of each titanocene derivative forming the dataset was built using the Sketcher module in the molecular modeling software SYBYL. ${ }^{49}$ The basic unit $\mathrm{Cp}_{2} \mathrm{TiCl}_{2}$ present in all titanocenes was modelled using the force field parameters reported by Doman et al. ${ }^{50}$ after converting them to the SYBYL format. Subsequent energy minimization was performed using the standard Tripos force field with a distance dependent dielectric constant and the Powell method with $0.05 \mathrm{kcal} / \mathrm{mol}$ ${ }_{30}$ energy gradient convergence criteria. The bond lengths and angles for the $\mathrm{Cp}_{2} \mathrm{TiCl}_{2}$ basic unit, obtained following minimization, were comparable to the reported values of the crystal structures of substituted titanocene compounds. ${ }^{26,33}$ Repeated minimization was performed with 1000 iterations, and 
each structure was obtained in its lowest energy conformer, which was used in the subsequent docking experiments in each case.

The crystal structures of HSA complexed with decanoic acid (capric acid) (PDBid 1E7E), diazepam 5 (PDBid 2BXF), ibuprofen (PDBid 2BXG) and warfarin (PDBid 2BXD) were obtained from the Protein Data Bank (PDB). ${ }^{51}$ In order to prepare HSA for the docking experiments duplicated chains, wherever present, as well as water molecules were removed. Additionally, all ligands such as capric acid, diazepam, ibuprofen and warfarin were extracted from the coordinate files of HSA complexed with capric acid (1E7E), diazepam (2BXF), ibuprofen (2BXG) and warfarin (2BXD), respectively. ${ }_{10}$ Finally, the protein structures were prepared for the docking runs using the Biopolymer Structure Preparation Tool implemented in the programme SYBYL. Docking experiments utilized the SurflexDock automatic docking algorithm. ${ }^{52}$ This compromises an empirical scoring function and a search engine to dock ligands into the protein ligand binding sites using a protomol-based method. ${ }^{52}$ Three different types of probes; hydrophobic, H-bond donor and H-bond acceptor were placed into each ${ }_{15}$ protein binding site in multiple positions and a scoring function then oriented the probes in order to optimize the interactions with the protein. High scoring probes represent "sticky spots", which are merged into a pocket. This pocket is called the protomol, which is a computational representation of the assumed ligands that interact within that binding site.

${ }_{20}$ The program PyMOL ${ }^{53}$ was used for visualization of the docking results. In order to calculate the hydrogen bond (H-bond), van der Waals (vdW) and hydrophobic interactions generated by the docking process, the resulting PDB files from the docking runs were input to the program CONTACT, available in the CCP4 programme suite. ${ }^{54}$ Potential H-bonds were assigned if the distance between two electronegative atoms was less than $3.3 \AA$, whereas any separation greater than $3.3 \AA$, but less than 4.0 ${ }_{25} \AA$ A, was considered a vdW interaction.

\section{Results and discussion}

\section{Validation of docking method}

The ligands; diazepam, ibuprofen (at two binding sites referred to ibuprofen 1 and ibuprofen 2) and ${ }_{30}$ warfarin were first extracted from the corresponding coordinate files; 2BXF, 2BXG and 2BXD, then docked again into each of the corresponding extracted files following the structure preparation procedures implemented in SYBYL program. This experiment revealed that each of these docked 
ligands was found to exactly dock into its corresponding ligand binding site in the protein structure. This provides a positive validation of the docking method used in the study.

\section{Docking studies}

${ }_{5}$ Two different types of docking runs were performed whereby; i) the ligand is centered and docked at a specified binding site and ii) the ligand is docked automatically in a binding site defined by the program.

Using the docking based approach on a pre-aligned ligand binding site, each of the modelled and ${ }_{10}$ minimized titanocene derivatives were docked sequentially into all four different ligand binding sites; warfarin, diazepam and the two ibuprofen sites used in the study. This is in addition to an automated docking process into the prepared HSA of (1E7E) which was not based on any ligand binding site, and a further docking process based on the fatty acid (capric acid) binding sites FA1, 2 and 5 of 1E7E (as defined by Curry et al. $)^{45}$

15

Table 2 summarizes the potential polar contacts and vdW interactions formed between the titanocenes under study and each of the potential ligand binding site residues in HSA as obtained following docking of each of the titanocenes into 2BXD (HSA complexed with warfarin), 2BXF (HSA complexed with diazepam) and 2BXG (HSA complexed with ibuprofen). Graphical representative ${ }_{20}$ examples of the docking results are presented in Fig.4.

\section{Docking at the warfarin binding site of (2BXD)}

Benzyl titanocenes, compounds 1a, 1b and 1c docked into the warfarin binding site of 2BXD were each found to make one H-bond interaction between the Ti center and the nitrogen center NZ of ${ }_{25}$ Lys199. Titanocene 1d was seen to form potential H-bonds by its chlorines with Glu292 and Lys199 of the HSA when docked into the warfarin binding site.

Docking of benzyl-substituted titanocenes $\mathbf{2 a}$ and $\mathbf{2 b}$ into the warfarin binding site of 2BXD revealed that potential H-bonds were formed between their chlorines and Gln196 and Lys199. 2a was found to ${ }_{30}$ show an additional H-bond between the oxygen center O(1) and OE2 atom of Glu292, while docking of 2c showed two H-bonds, one formed between the Ti center and the nitrogen center NZ of Lys199 and the other between $\mathrm{Cl}(2)$ and the backbone oxygen atom of Ala291.

This journal is (C) The Royal Society of Chemistry [year] Journal Name, [year], [vol], 00-00|7 
Bis-amino-functionalized titanocenes, compounds $\mathbf{3 a}, \mathbf{3 b}$ and $\mathbf{3 c}$ docked into the warfarin binding site of $2 \mathrm{BXD}$ showed that titanocene 3a formed only one $\mathrm{H}$-bond, between its chlorine center $\mathrm{Cl}(1)$ and the nitrogen atom NE2 of His242. In comparison titanocene $\mathbf{3 b}$ formed three $\mathrm{H}$-bonds, one between $\mathrm{Cl}(1)$ 5 and His242 and the other two between N(4), S(2) and Lys199. On the other hand, titanocene 3c was shown to form four H-bonds, two between $\mathrm{Cl}(1)$ and Arg222/Ala291, one between the other chlorine center and Lys199 and one between N(3) and Glu292.

Docking of achiral diheteroaryl-substituted titanocene $4 \mathbf{a}$ into the warfarin binding site of 2BXD was ${ }_{10}$ found to form two H-bonds, by $\mathrm{Cl}(1)$ and $\mathrm{O}(4)$ with $\mathrm{Arg} 222$ and Lys199 respectively. In contrast, titanocene 4b showed three potential H-bonds, two between $\mathrm{Cl}(2)$ and $\operatorname{Arg} 222 / \mathrm{Ala} 291$ and one between S(4) with Glu292. Compound 4c exhibited two H-bonds between $\mathrm{Cl}(2)$ to both $\operatorname{Arg} 222$ and Ala291.

${ }_{15}$ Docking of achiral diaryl-substituted titanocene 5a showed a network of eight potential H-bonds, formed by $\mathrm{Cl}(1), \mathrm{O}(1), \mathrm{O}(5)$ and $\mathrm{O}(6)$ atoms to Lys199, Arg222, Lys195 and Glu292, respectively, and four H-bonds were shown between $\mathrm{O}(3)$ and Arg257, His288 and Ser287. Compound 5b appeared capable of making three H-bonds, two by its chlorine atoms to Lys199 and one between N(4) atom to Glu292. And compound 5c showed the formation of two H-bonds, between its Ti, O1 atoms and ${ }_{20}$ Arg222/Arg257, respectively.

\section{Docking at the diazepam binding site of (2BXF)}

Docking of 1a into the diazepam binding site of 2BXF was found to form two H-bonds between the chlorine center $\mathrm{Cl}(2)$ and both the oxygen atom OG of Ser489 and the $\mathrm{OH}$ group of Tyr411. Whereas ${ }_{25} \mathbf{1 b}$ and 1c were each shown to form three H-bonds by their chlorines to OG atom of Ser489 and OH group of Tyr411. In addition, 1b was shown to form two further H-bonds between the oxygen center $\mathrm{O}(2)$ and side chain atoms ND2 and the backbone nitrogen of Asn391, whereas 1c was shown to form another H-bond between the oxygen center O(4) and SG atom of Cys392. Docking of 1d resulted in two H-bonds that were formed from its chlorines with Asn391 and Arg410.

30

On the other hand, docking of $\mathbf{2 a}, \mathbf{2} \mathbf{b}$ and $\mathbf{2 c}$ into the diazepam binding site gave different interactions. Compound $\mathbf{2 a}$ was found to form a single $\mathrm{H}$-bond between the chlorine center $\mathrm{Cl}(2)$ and $\mathrm{OG}$ atom of 
Ser489. Compound $\mathbf{2 b}$ was also found to form a single $\mathrm{H}$-bond between $\mathrm{Cl}(1)$ and $\mathrm{OH}$ group of Tyr411, whereas compound 2c showed four H-bond interactions, two formed through $\mathrm{Cl}(2)$ with both OG atom of Ser489 and OH group of Tyr411, and two formed between its N(1) with side chain atoms NE and NH2 of Arg410.

Docking 3a into the diazepam binding site formed three H-bonds, two between the chlorine center $\mathrm{Cl}(2)$ to both Ser489 and Tyr411, and the other one with N(6) atom to Asn391. Docking 3b showed only two H-bonds through the chlorine $\mathrm{Cl}(1)$ and the nitrogen $\mathrm{N}(6)$ centers with the side chain atoms ND2 and OD1 of Asn391, respectively. Compound 3c appears able to form four H-bonds, two with the ${ }_{10}$ chlorine centers $\mathrm{Cl}(1)$ and $\mathrm{Cl}(2)$ to ND2 atom of Asn391 and $\mathrm{OH}$ group of Tyr411, respectively, and two by the nitrogen centers N(1) and N(6) to the side chain atoms NE of Arg410 and OD1 of Asn391, respectively.

Compound 4a docked into the diazepam binding site of 2BXF was shown to form four H-bonds, two ${ }_{15}$ between its chlorines with Asn391 and Tyr411 and two through the oxygen centers $\mathrm{O}(1)$ and $\mathrm{O}(3)$ to Asn391. Compound 4b showed two H-bonds through its chlorines to Asn391 and Tyr411. And compound $\mathbf{4 c}$ was shown to form three potential H-bonds by its chlorines with Asn391.

Compound 5a docked into the diazepam binding site of 2BXF was shown to form seven H-bonds, two ${ }_{20}$ between the chlorine centers $\mathrm{Cl}(1), \mathrm{Cl}(2)$ with $\mathrm{Arg} 485$ and Asn391, respectively, and the other five through the oxygen centers $\mathrm{O}(3), \mathrm{O}(5), \mathrm{O}(6), \mathrm{O}(7)$ and $\mathrm{O}(8)$ with Ser489, Cys392, Gly434, Tyr411 and Asn391, respectively. 5b was shown to form five H-bonds, one by $\mathrm{Cl}(1)$ with Tyr411, three by the nitrogen center $\mathrm{N}(2)$ with Arg485 and Glu450, and one by the nitrogen center N(3) with Gln390. 5c was found to form five H-bonds, three through its chlorines with both Ser489 and Tyr411, and two by ${ }_{25}$ the oxygen centers $\mathrm{O}(3)$ and $\mathrm{O}(4)$ with Gly434 and Glu450, respectively.

\section{Docking at the ibuprofen binding site of (2BXG)}

No polar contacts were found with any of the amino acid residues upon docking of titancenes 1a and

$\mathbf{1 d}$ into the ibuprofen binding site of $2 \mathrm{BXG}$, whereas docking of $\mathbf{1 b}$ and $\mathbf{1 c}$ showed $\mathrm{H}$-bonds between ${ }_{30}$ their chlorines with both Arg410 and Asn391. 
Docking of $\mathbf{2 a}, \mathbf{2 b}$ and $\mathbf{2 c}$ into the ibuprofen binding site were found to form potential H-bonds between their chlorines and Asn391 and Arg410. Additional H-bonds were shown through O(1) center of $\mathbf{2 a}$ to Lys414 and through N(2) center of $\mathbf{2 c}$ to both Lys414 and Ser489.

${ }_{5}$ Compound 3a docked into the ibuprofen binding site of 2BXG was shown capable of forming a total of six H-bonds, two between its chlorines to Ser489 and Asn391, two between the oxygen center O(4) to Asn391, and two through O(1), N(5) atoms to Arg410 and Ser489, respectively. Compound 3b was found to form five H-bonds, three by its chlorines to Lys414 and Ser489 and two by S(4) with Asn391. And compound 3c exhibited a network of five potential H-bonds through its chlorines with Arg410 ${ }_{10}$ and Asn391.

Compound 4a was found to form a network of five potential H-bonds, four through its chlorines with Arg410 and Asn391 and one by $\mathrm{O}(4)$ center with Arg410. Compound 4b showed a total of five Hbonds between its chlorines with Arg410 and Asn391. And compound 4c was found to form four $\mathrm{H}-$ ${ }_{15}$ bonds, two through its chlorines with Asn391 and another two by the nitrogen centers N(2) and N(4) with Asn391 and Arg410, respectively.

Docking of compound 5a appeared capable of making a network of eight potential H-bonds, three between chlorine center $\mathrm{Cl}(2)$ with $\mathrm{NH} 1, \mathrm{NH} 2$ atoms of Arg410 and OD1 atom of Asn391, one ${ }_{20}$ between Ti center with Arg410, and four through the oxygen centers; O(6) with Leu430 and O(8) with Ser489 and Arg485. Compound 5b showed two H-bonds through $\mathrm{Cl}(1)$ with $\operatorname{Arg} 410$. And compound 5c was shown to form four H-bonds, three between its chlorines with Lys414 and Ser489, and one through $\mathrm{O}(4)$ center with Tyr411.

\section{${ }_{25}$ The automated docking site}

Table 3 lists the polar contacts together with the vdW interactions between titanocenes under study and HSA (1E7E) as found by automated docking run.

The automated docking process was run without taking into account a specific ligand binding site. All titanocenes under investigation were shown to form several potential $\mathrm{H}$-bonds and vdW interactions ${ }_{30}$ with different amino acid residues from both binding sites; drug site I and drug site II. Actually interactions were shown with the following amino acid residues: Lys195, Leu198, Lys199, Phe211, Trp214, Arg218, Val344, Glu450, Asp451, Leu453, Ser454, Leu481 and Arg485. 
Automated docking revealed that these titanocenes can bind at a different site than previously identified for HSA. In fact, instead of binding to either known drug binding sites I and II, these compounds appear to span a large region making several potential H-bonds and vdW interactions with amino acid residues from both known drug binding sites, drug site I and II on HSA. This is not ${ }_{5}$ surprising when the actual size of these compounds is taken into account.

\section{Overall comparison of potential binding sites}

Proteins in general, contain pockets (or cavities) where small ligands (peptides, nucleic acids, sugars, organic molecules, metals, etc) can bind. Furthermore, it is well known that proteins are flexible ${ }_{10}$ molecules that can accommodate ligands with vastly different sizes and shapes. Importantly, there are several factors that have a significant impact on the strength and specificity of ligand binding, such as lipophilicity, H-bonding potential and complementarity in shape. Minor structural modifications can have unpredictable effects on drug binding.

${ }_{15}$ Generally speaking, higher cytotoxic activity $\mathrm{IC}_{50}$ range (21-120) $\mu \mathrm{M}$ was observed for benzylsubstituted titanocenes 1a-d compared to the heteroaryl-substituted titanocenes $\mathbf{2 a - c}$ with $\mathrm{IC}_{50}$ range (91-160) $\mu \mathrm{M}$. This could be due to a higher number of vdW interactions that were made by titanocenes 1a-d at drug site I compared to that of $\mathbf{2 a - c}$.

Benzyl-sustituted titanocene with $p$-methoxy group, compound $\mathbf{1 b}$ showed an impressive 10-fold ${ }_{20}$ increase in cytotoxicity compared to its $\mathrm{NMe}_{2}$ substituted analogue $\mathbf{1 a}$. This possibly could be due to the larger number of vdW interactions that titanocene $\mathbf{1 b}$ is forming compared to $\mathbf{1 a}$.

A comparison of the docking results for compounds $\mathbf{2 a - c , 3 a - c}$ and $\mathbf{4 a - c}$ with their cytotoxic activity revealed a general observation. As a general trend, compounds bearing $N$-methylpyrrol substitution on the cyclopentadienyl rings were shown to have higher cytotoxic activity than those where the ${ }_{25}$ substitution is a thienyl or furyl group. Investigating the types of interactions, it was observed that compounds with $N$-methylpyrrol substitution made H-bonds through their methylamino groups with thr nitrogen atoms of the side chain Arg410, suggesting the importance of this type of interaction with HSA on the cytotoxic activity of these compounds.

Comparison of mono- and di-heteroaryl substituted titanocenes with the $N$-methyl pyrrol substitution, ${ }_{30} \mathbf{2 c}$ and $\mathbf{4 c}$ showed that compound $\mathbf{4 c}$ exhibited higher number of vdW interactions at drug sites I and II than did compound $\mathbf{2 c}$ which could explain the differences in their cytotoxic activity. 
Furthermore, although compound $\mathbf{4 c}$ makes fewer H-bonds compared to $\mathbf{4 a}$ or $\mathbf{4 b}$, it has higher cytotoxic activity than either $\mathbf{4 a}$ or $\mathbf{4 b}$. This may suggest that vdW interactions play an important role in its binding mode to HSA, hence the outcome on cytotoxic activity (since $\mathbf{4 c}$ makes a larger number of vdW interactions with residues in the warfarin binding site).

s On the other hand, diaryl-substituted titanocene $\mathbf{5 b}$ have higher cytotoxic activity when compared to the monoaryl-substituted titanocene 1a. This is probably because of large number of H-bonds that titanocene $\mathbf{5 b}$ formed with the amino acid residues of both drug site I and drug site II of HSA.

These differences highlighted the importance of molecular descriptors, such as H-bonding potential, lipophilicity and shape complemantarity in determining the binding mode to HSA.

The docking results to date indicate that these titanocenes can make several interactions through $\mathrm{H}$ bonding and vdW interactions with amino acid residues of the warfarin binding site of 2BXD (known as drug site I), as well as with those of diazepam and ibuprofen binding sites of $2 \mathrm{BXF}$ and $2 \mathrm{BXG}$ (known as drug site II).Thus, it is plausible that these titanocenes can bind HSA at either primary ${ }_{15}$ binding sites I and II located in subdomains IIA and IIIA, respectively. Otherwise, these titanocenes, like ibuprofen, may bind at multiple sites on HSA. Certainly, the numerous H-bonds shown by compounds suggest that these titanocenes show high specificity towards drug site I, and/or drug site II. Docking results for drug site II based on diazepam and ibuprofen binding sites, suggested that these titanocenes may bind in slightly two different positions within the binding site itself, however this ${ }_{20}$ cannot be substantiated without experimental evidence. More specifically, docking results showed that these titanocenes were found to make interactions with the amino acid residues of HSA at different fatty acid (FA) sites, but no interactions were noticed with the amino acid residues at FA1, 2 and 5 sites. Therefore, in order to gain insight at the whole picture of the binding mode of these titanocenes at different possible binding sites, further docking processes based on FA1, FA2 and FA5 sites were ${ }_{25}$ run. Interestingly, docking of these titanocenes into fatty acid sites 1 (FA1), 2 (FA2) and 5 (FA5) of 1E7E revealed that the ligands were more exposed to the solvent (Fig. 5) which may be indicative of weaker and less specific binding at these sites on HSA. Furthermore, automated docking revealed an alternative binding pocket for these titanocenes to bind, which again requires experimental data to substantiate.

\section{Conclusions}


Our results indicate potential binding through H-bonding and van der Waals (vdW) interactions of these titanocenes to human serum albumin at the known drug binding sites. Additionally, we hypothesize a new alternative binding site for these titanocenes that spans two of the known drug binding sites. Based on the comprehensive docking studies performed herein, these titanocene ${ }_{5}$ derivatives may bind to either of the HSA primary drug binding sites I or II, or, alternatively these molecules may bind to multiple sites, as observed with other drugs such as ibuprofen.

This work provides new insight into the specificity and shape complementarity of binding of these titanocenes to each known drug binding pocket in HSA and reveals a potentially new binding pocket ${ }_{10}$ for these derivatives. Site-directed mutagenesis studies, as well as X-ray crystallographic analysis of ligand-protein complexes can provide validation of the most likely ligand binding site(s) for the titanocene derivatives. This work is currently underway.

\section{Acknowledgements}

${ }_{15}$ We extend our gratitude to the Ministry of Higher Education and Scientific Research in Iraq for financial support to Susan Sarsam. We thank Sue Mitchell (Structural Biology Unit, The BioCentre) for providing excellent computing support. 


\section{References}

1. B. Rosenberg, L. Vancamp, J. E. Trosko and V. H. Mansour, Nature, 1969, 222, 385-386.

2. E. Wong and C. M. Giandomenico, Chem. Rev., 1999, 99, 2451-2466.

3. E. Melendez, Critical Reviews in Oncology/Hematoology, 2002, 42, 309-315.

54. M. M. Harding and G. Mokdsi, Current Medicinal Chemistry, 2000, 7, 1289-1303.

5. G. Lummen, H. Sperling, H. Luboldt, T. Otto and H. Rubben, Cancer Chemother. Pharmacol., 1998, 42, 415-417.

6. N. Kröger, U. R. Kleeberg, K. Mross, L. Edler and D. K. Hossfeld, Oncologie, 2000, 23, 60-62.

7. A. Vessieres, M-A. Plamont, C. Cabestaing, J. Claffey, S. Dieckmann, M. Hogan, H. Müller${ }_{10}$ Bunz, K. Strohfeldt and M. Tacke, Journal of Organometallic Chemistry, 2009, 694, 874-879.

8. O. R. Allen, A. L.Gott, J. A. Hartley, J. M. Hartley, R. J. Knox and P. C. McGowan, Dalton Trans., 2007, 5082-5090.

9. O. R. Allen, L. Croll, A. L. Gott, R. J. Knox and P. C. McGowan, Organometallics, 2004, 23, 288-292.

15 10. M. McGowan and P. C. McGowan, Inorganic Chemistry Communications, 2000, 3, 337-340.

11. P. W. Causey and M. C. Baird, Organometallics, 2004, 23, 4486-4494.

12. K. Strohfeldt and M. Tacke, Chem. Soc. Rev., 2008, 37, 1174-1187.

13. C. M. Dowling, J. Claffey, S. Cuffe, I. Fichtner, C. Pampillon, N. J. Sweeney, K. Strohfeldt, W. R. Watson and M. Tacke, Letters in Drug Design \& Discovery, 2008, 5, 141-144.

20 14. C. Pampillón, J. Claffey, K. Strohfeldt and M. Tacke, Eur. J. Med. Chem., 2008, 43(1), 122128.

15, C. Pampillon, J. Claffey, E. Hogan and M. Tacke, BioMetals, 2008, 21, 197-204.

16. K. Strohfeldt, H. Müller-Bunz, C. Pampillón and M. Tacke, Transition Metal Chem., 2007 , 32(7), 971-980.

25 17. J. H. Bannon, I. Fichtner, A. O'Neill, C. Pampillon, N. J. Sweeney, K Strohfeldt, R. W. Watson, M. Tacke and M. M. Mc Gee, British Journal of Cancer, 2007, 97, 1234-1241.

18. H. Müller-Bunz, I. Dix, Y. Lou, C. Pampillón, K. Strohfeldt, N. J. Sweeney and M. Tacke, Z. Kristallogr, 2007, 222, 376-382.

19. C. Pampillón, J. Claffey, M. Hogan, K. Strohfeldt and M. Tacke, Trans. Met. Chem., 2007, 32, ${ }_{30} 434-441$.

20. C. Pampillón, N. J. Sweeney, K. Strohfeldt and M. Tacke, J. Organomet. Chem., 2007, 692, 2153-2159. 
21. N. J. Sweeney, J. Claffey, H. Müller-Bunz, C. Pampillón, K. Strohfeldt and M. Tacke, Appl. Organomet. Chem., 2007, 21, 57-65.

22. O. Oberschmidt, A.-R. Hanauske, C. Pampillón, K. Strohfeldt, N. J. Sweeney and M. Tacke, Anti-Cancer Drugs, 2007, 18, 317-321.

s 23. P. Beckhove, A.-R. Hanauske, O. Oberschmidt, C. Pampillón, V. Schirrmacher, N. J. Sweeney, K. Strohfeldt and M. Tacke, Anti-Cancer Drugs, 2007, 18, 311-315.

24. K. Strohfeldt, H. Müller-Bunz, C. Pampillion, N. J. Sweeney and M. Tacke, Eur. J. Inorg. Chem., 2006, 4621-4628.

25. C. Pampillón, N. Sweeney, K. Strohfeldt and M. Tacke, Inorg. Chim. Acta, 2006, 359, 3969${ }_{10} 3975$.

26. N. J. Sweeney, W. M. Gallagher, H. Müller-Bunz, C. Pampillón, K. Strohfeldt and M. Tacke, J. Inorg. Biochem., 2006, 100, 1479-1486.

27. K. O’Connor, C. Gill, M. Tacke, F.-J. K. Rehmann, K. Strohfeldt, N. Sweeney, J. M. Fitzpatrick and R. W. G. Watson, Apoptosis, 2006, 11, 1205-1214.

${ }_{15}$ 28. C. Pampillón, K. Strohfeldt, N. J. Sweeney and M. Tacke, Polyhedron, 2006, 25, 2101-2108.

29. M. C. Valadares, A. L. Ramos, F.-J. K. Rehmann, N. J. Sweeney, K. Strohfeldt, M. Tacke and M. L. S. Queiroz, Eur. J. of Pharmacolgy, 2006, 534, 264-270.

30. I. Fichtner, C. Pampillón, N. J. Sweeney, K. Strohfeldt and M. Tacke, Anti-Cancer Drugs, 2006, 17, 333-336.

${ }_{20}$ 31. O. Oberschmidt, A.-R. Hanauske, F.-J. K. Rehmann, K. Strohfeldt, N. Sweeney and M. Tacke, Anti-Cancer Drugs, 2005, 16, 1071-1073.

32. G. Kelter, N. J. Sweeney, K. Strohfeldt, H.-H. Fiebig and M. Tacke, Anti-Cancer Drugs, 2005, 16, 1091-1098.

33. N. J. Sweeney, O. Mendoza, H. Müller-Bunz, C. Pampillón, F.-J. K. Rehmann, K. Strohfeldt ${ }_{25}$ and M. Tacke, J. Organomet. Chem., 2005, 690, 4537-4544.

34. F.-J. K. Rehmann, A. J. Rous, O. Mendoza, N. J. Sweeney, K. Strohfeldt, W. M. Gallagher and M. Tacke, Polyhedron, 2005, 24(11), 1250-1255.

35. F.-J. K. Rehmann, L. P. Cuffe, O. Mendoza, D. K. Rai, N. Sweeney, K. Strohfeldt, W. M. Gallagher and M. Tacke, Appl. Organomet. Chem., 2005, 19, 293-300.

${ }_{30}$ 36. P. M. Abeysinghe and M. M. Harding, Dalton Trans., 2007, 3474-3482.

37. M. Guo and P. J. Sadler, J. Chem. Soc., Dalton Trans., 2000, 7-9. 
38. M. Guo, H. Sun, H. J. McArdle, L. Gambling and P. J. Sadler, Biochemistry, 2000, 39, 1002310033.

39. A. D. Tinoco, E. V. Eames and A. M. Valentine, J. Am. Chem. Soc., 2008, 130, 2262-2270.

40. P. Köpf-Maier, J. Structural. Biol., 1990, 105, 35-45.

541. M. L. McLaughlin, J. M. Cronan, Jr., T. R. Schaller and R. D. Snelling, J. Am. Chem. Soc., 1990, 112, 8949-8952.

42. Z. Zhang, P. Yang, M. Guo and H. Wang, Journal of Inorganic Biochemistry, 1996, 63, 183190.

43. X. M. He and D. C. Carter, Nature, 1992, 358, 209-215.

${ }_{10}$ 44. J. Tang, N. Liam, X. He and G. Zhang, Journal of Molecular Structure, 2008, 889, 408-414.

45. A. A. Bhattacharya, T. Grüne and S. Curry, J. Mol. Biol., 2000, 303, 721-732.

46. J. Ghuman, P. A. Zunszain I. Petitpas, A. A. Bhattacharya, M. Otagirl and S. Curry, J. Mol. Biol. 2005, 353, 38-52.

47. S.-H. Lee, H. T. M. Van, S. H. Yang, K.-T. Lee, Y. Kwon and W.-J. Cho, Bioorganic \& 15 Medicinal Chemistry Letters, 2009, 19, 2444-2447.

48. M. Montembault, G. Vo-Thanh, A. Deyine, V. Fargeas, M. Villieras, A. Adjou, D. Dubreuil, D. Esquieu, C. Gregoire, S. Opi, J.-M. Peloponese, G. Campbell, J. Watkins, J. Mareuil, A.-M. Aubertin, C. Bailly, E. Loret and J. Lebreton, Bioorganic \& Medicinal Chemistry Letters, 2004, 14, 1543-1546.

${ }_{20} 49 . \quad$ Sybyl 8.0 Tripos Associates Inc., St. Louis, MC, 2007.

50. T. N. Doman, T. K. Hollis and B. Bosnich, J. Am. Chem. Soc., 1995, 117, 1352-1368.

51. http://www.ebi.ac.uk.

52. A. N. Jain, J. Med. Chem. 2003, 46, 499-511.

53. PyMOL DeLano Scientific LLC, 2006.

${ }_{25}$ 54. Collaborative Computational Project, Number 4. "The CCP4 Suite: Programs for Protein Crystallography". Acta Crystallogr. 1994, D50, 760-763. 
Table 1

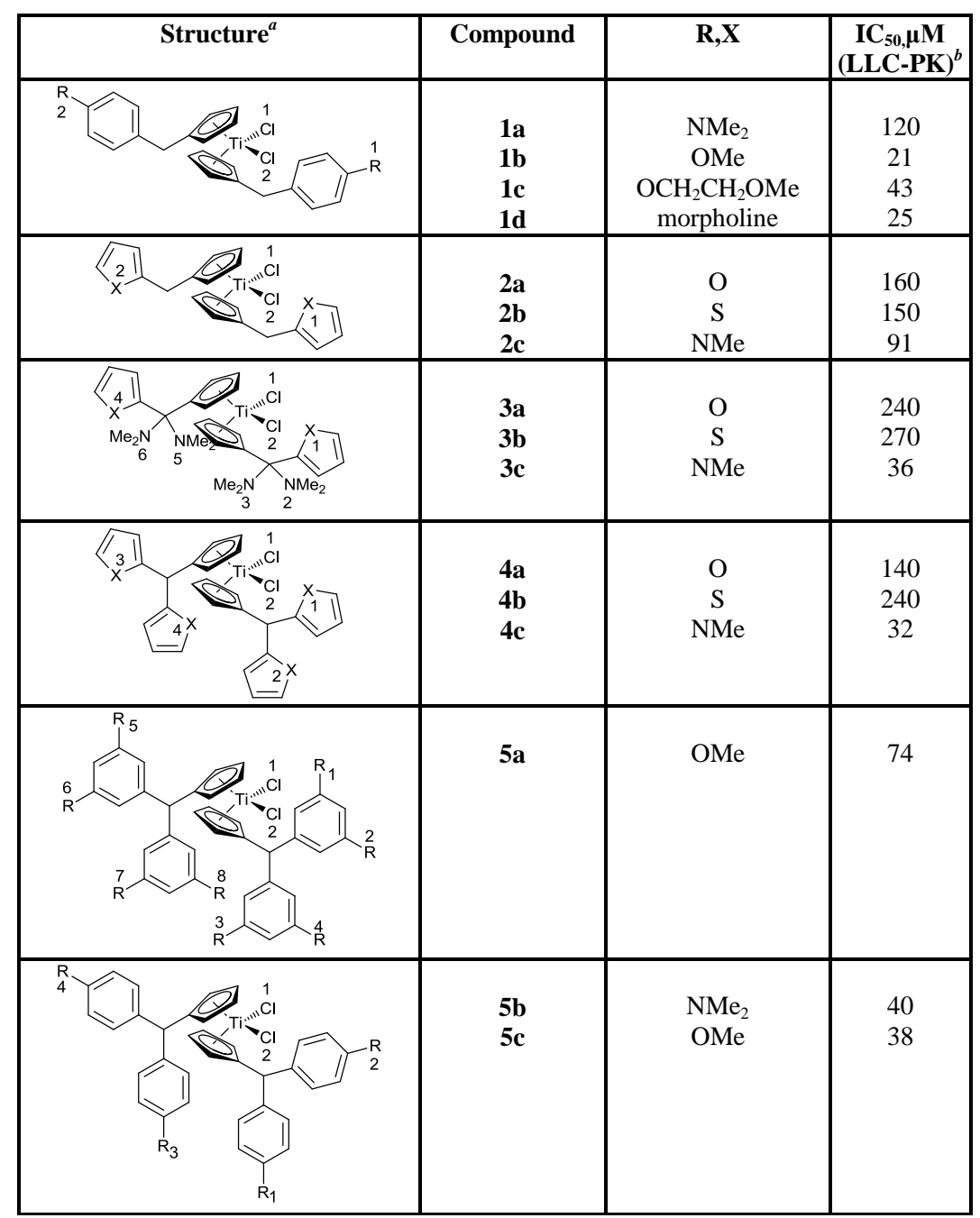

${ }^{a}$ Select atoms are numbered for ease of identification in the results section ${ }^{b}$ LLC-PK Kidney carcinoma cell line 
Table 2.

\begin{tabular}{|c|c|c|c|c|c|c|c|c|c|}
\hline \multirow{3}{*}{$\begin{array}{c}\text { Compound } \\
\mathbf{1 a}\end{array}$} & \multicolumn{6}{|c|}{ H-bonds with Distances $(\AA)^{a}$} & \multicolumn{3}{|c|}{$\begin{array}{l}\text { Number of vdW } \\
\text { interactions }\end{array}$} \\
\hline & \multicolumn{2}{|c|}{ Drug-site $\mathrm{I}^{b}$} & \multicolumn{2}{|c|}{ Drug-site II ${ }^{c}$} & \multicolumn{2}{|c|}{ Drug-site II $^{d}$} & \multirow{2}{*}{$\frac{\text { Drug-site } \mathrm{I}^{b}}{72}$} & \multicolumn{2}{|c|}{ Drug-site II $^{c, d}$} \\
\hline & Ti...NZ Lys199 & 3.07 & $\begin{array}{l}\mathrm{Cl} 2 \ldots \text { OG Ser } 489 \\
\mathrm{C} 22 \ldots \text { OH Tyr } 411\end{array}$ & $\begin{array}{l}2.98 \\
2.77\end{array}$ & - & & & 62 & 49 \\
\hline 1b & Ti...NZ Lys199 & 3.02 & 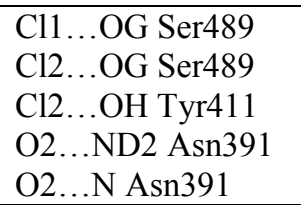 & $\begin{array}{l}3.01 \\
2.91 \\
2.71 \\
3.21 \\
2.91\end{array}$ & 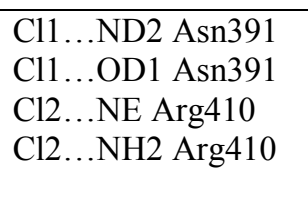 & $\begin{array}{l}3.03 \\
2.81 \\
2.96 \\
2.50\end{array}$ & 79 & 67 & 63 \\
\hline 1c & Ti...NZ Lys199 & 3.16 & 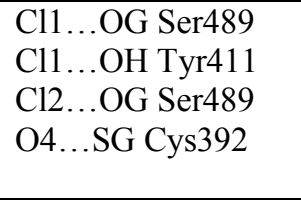 & $\begin{array}{l}3.17 \\
2.83 \\
3.05 \\
3.03\end{array}$ & 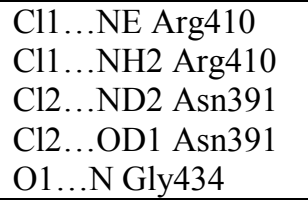 & $\begin{array}{l}3.07 \\
2.67 \\
3.18 \\
2.97 \\
3.17\end{array}$ & 74 & 65 & 84 \\
\hline 1d & $\begin{array}{l}\text { Cl1....OE2 Glu292 } \\
\text { Cl2...NZ Lys199 }\end{array}$ & $\begin{array}{l}2.79 \\
2.26\end{array}$ & $\begin{array}{l}\text { Cl1...OD1 Asn391 } \\
\text { Cl2...NE Arg410 }\end{array}$ & $\begin{array}{l}3.18 \\
3.14\end{array}$ & - & & 87 & 72 & 40 \\
\hline $2 \mathbf{a}$ & $\begin{array}{l}\mathrm{Cl} 2 \ldots \mathrm{OE} 1 \mathrm{G} \ln 196 \\
\mathrm{Cl} 2 \ldots \mathrm{NZ} \text { Lys199 } \\
\text { O1...OE2 Glu292 }\end{array}$ & $\begin{array}{l}3.29 \\
2.73 \\
2.97\end{array}$ & $\mathrm{Cl} 2 \ldots \mathrm{OG}$ Ser489 & 3.01 & 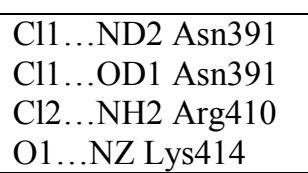 & $\begin{array}{l}2.83 \\
2.75 \\
2.57 \\
2.82\end{array}$ & 50 & 67 & 56 \\
\hline $2 \mathbf{b}$ & $\begin{array}{l}\text { Cl1...OE1 Gln196 } \\
\text { Cl1...NZ Lys199 }\end{array}$ & $\begin{array}{l}3.10 \\
3.21\end{array}$ & Cl1...OH Tyr411 & 2.61 & 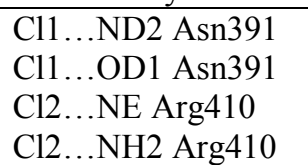 & $\begin{array}{l}2.94 \\
2.75 \\
3.08 \\
2.60\end{array}$ & 50 & 68 & 58 \\
\hline $2 c$ & $\begin{array}{l}\text { Ti...NZ Lys199 } \\
\text { Cl2...O Ala291 }\end{array}$ & $\begin{array}{l}3.00 \\
3.22\end{array}$ & $\begin{array}{l}\mathrm{Cl} 2 \ldots \text { OG Ser489 } \\
\mathrm{Cl} 2 \ldots \mathrm{OH} \text { Tyr411 } \\
\mathrm{N} 1 \ldots \mathrm{NE} \text { Arg410 } \\
\mathrm{N} 1 \ldots \mathrm{NH} 2 \text { Arg410 }\end{array}$ & $\begin{array}{l}2.78 \\
2.86 \\
3.00 \\
3.07\end{array}$ & 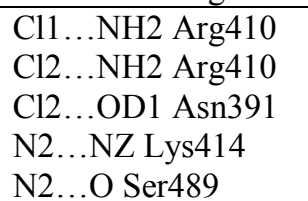 & $\begin{array}{l}2.76 \\
2.95 \\
2.10 \\
3.12 \\
3.29\end{array}$ & 45 & 56 & 79 \\
\hline
\end{tabular}


Table 2 (con't)

\begin{tabular}{|c|c|c|c|c|c|c|c|c|c|}
\hline \multirow[t]{2}{*}{ Compound } & \multicolumn{6}{|c|}{ H-bonds with Distances $(\AA)^{a}$} & \multicolumn{3}{|c|}{$\begin{array}{l}\text { Number of vdW } \\
\text { interactions }\end{array}$} \\
\hline & \multicolumn{2}{|l|}{ Drug-site I ${ }^{b}$} & \multicolumn{2}{|c|}{ Drug-site II ${ }^{c}$} & \multicolumn{2}{|c|}{ Drug-site II $^{d}$} & Drug-site $\mathbf{I}^{b}$ & Drt & $\mathrm{II}^{c, d}$ \\
\hline $3 \mathbf{a}$ & Cl1...NE2 His242 & 3.29 & $\begin{array}{l}\mathrm{Cl} 2 \ldots \text {.OG Ser489 } \\
\text { Cl2...OH Tyr411 } \\
\text { N6...OD1 Asn391 }\end{array}$ & $\begin{array}{l}3.16 \\
3.22 \\
2.92\end{array}$ & 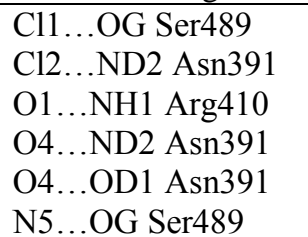 & \begin{tabular}{|c|}
2.55 \\
3.07 \\
3.03 \\
2.65 \\
3.04 \\
3.16
\end{tabular} & 90 & 59 & 48 \\
\hline 3b & $\begin{array}{l}\text { C11...NE2 His } 242 \\
\text { N4...NZ Lys199 } \\
\text { S2...NZ Lys199 }\end{array}$ & $\begin{array}{l}3.23 \\
3.04 \\
2.55\end{array}$ & $\begin{array}{c}\text { C11...ND2 Asn391 } \\
\text { N6...OD1 Asn391 }\end{array}$ & $\begin{array}{l}2.23 \\
2.93\end{array}$ & 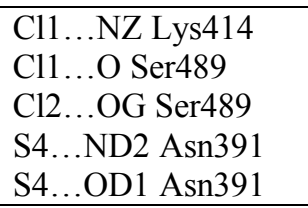 & $\begin{array}{l}3.23 \\
2.97 \\
2.18 \\
2.12 \\
2.78 \\
\end{array}$ & 75 & 60 & 53 \\
\hline $3 c$ & 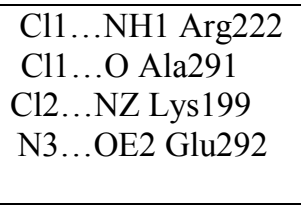 & $\begin{array}{l}2.99 \\
2.67 \\
2.98 \\
3.27\end{array}$ & 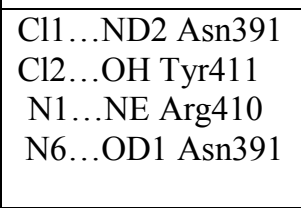 & $\begin{array}{l}2.35 \\
3.10 \\
3.09 \\
2.92\end{array}$ & $\begin{array}{l}\mathrm{Cl} 1 \ldots \mathrm{NE} \text { Arg410 } \\
\mathrm{Cl1} \ldots \mathrm{NH} 2 \text { Arg410 } \\
\mathrm{Cl} 2 \ldots \mathrm{NH} 2 \text { Arg410 } \\
\mathrm{Cl} 2 \ldots \mathrm{ND} 2 \text { Asn391 } \\
\mathrm{Cl} 2 \ldots \mathrm{OD} 1 \text { Asn391 }\end{array}$ & \begin{tabular}{|l|}
2.42 \\
2.93 \\
2.69 \\
3.27 \\
2.57
\end{tabular} & 81 & 79 & 60 \\
\hline $4 a$ & $\begin{array}{l}\text { Cl1...NH1 Arg222 } \\
\text { O4...NZ Lys199 }\end{array}$ & $\begin{array}{l}3.12 \\
2.66\end{array}$ & 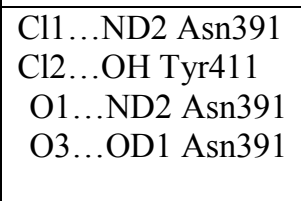 & $\begin{array}{l}2.82 \\
3.10 \\
3.10 \\
3.02\end{array}$ & $\begin{array}{l}\mathrm{C} 11 \ldots \mathrm{NE} \text { Arg410 } \\
\mathrm{Cl} 1 \ldots \mathrm{NH} 2 \text { Arg410 } \\
\mathrm{Cl} 2 \ldots \mathrm{NH} 2 \text { Arg410 } \\
\mathrm{Cl} 2 \ldots \mathrm{OD} 1 \text { Asn391 } \\
\text { O } 4 \ldots \text { NE Arg410 }\end{array}$ & \begin{tabular}{|l|}
2.90 \\
2.92 \\
2.34 \\
2.20 \\
2.98
\end{tabular} & 70 & 77 & 83 \\
\hline $4 \mathrm{~b}$ & $\begin{array}{l}\mathrm{Cl} 2 \ldots \mathrm{NH} 1 \mathrm{Arg} 222 \\
\mathrm{C} 12 \ldots \mathrm{O} \text { Ala291 } \\
\text { S4...OE2 Glu292 }\end{array}$ & $\begin{array}{l}2.96 \\
3.06 \\
2.56\end{array}$ & $\begin{array}{l}\text { Cl1....ND2 Asn391 } \\
\text { Cl2...OH Tyr411 }\end{array}$ & $\begin{array}{l}2.79 \\
3.16\end{array}$ & $\begin{array}{l}\mathrm{Cl} 1 \ldots \mathrm{NE} \text { Arg410 } \\
\mathrm{Cl} 1 \ldots \mathrm{NH} 2 \text { Arg410 } \\
\mathrm{Cl} 2 \ldots \mathrm{NH} 1 \text { Arg4 } 410 \\
\mathrm{Cl} 2 \ldots \mathrm{NH} 2 \text { Arg410 } \\
\mathrm{Cl} 2 \ldots \mathrm{OD} 1 \text { Asn391 }\end{array}$ & \begin{tabular}{l|}
2.38 \\
3.25 \\
3.28 \\
2.24 \\
2.65
\end{tabular} & 88 & 62 & 73 \\
\hline $4 c$ & $\begin{array}{l}\mathrm{Cl} 2 \ldots \mathrm{NH} 1 \mathrm{Arg} 222 \\
\mathrm{C} 12 \ldots \mathrm{O} \text { Ala291 }\end{array}$ & $\begin{array}{l}2.99 \\
2.85\end{array}$ & 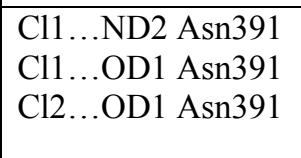 & $\begin{array}{l}2.29 \\
3.20 \\
2.97\end{array}$ & 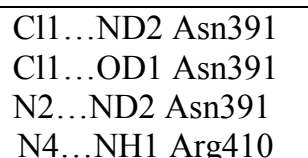 & \begin{tabular}{l|}
2.87 \\
2.74 \\
3.30 \\
3.24
\end{tabular} & 93 & 68 & 73 \\
\hline
\end{tabular}




\section{Table 2 (con't)}

\begin{tabular}{|c|c|c|c|c|c|c|c|c|c|}
\hline \multirow{3}{*}{$\begin{array}{c}\text { Compound } \\
\mathbf{5 a}\end{array}$} & \multicolumn{6}{|c|}{ H-bonds with Distances $(\AA)^{a}$} & \multicolumn{3}{|c|}{$\begin{array}{l}\text { Number of vdW } \\
\text { interactions }\end{array}$} \\
\hline & \multicolumn{2}{|l|}{ Drug-site $\mathrm{I}^{b}$} & \multicolumn{2}{|l|}{ Drug-site II ${ }^{c}$} & \multicolumn{2}{|l|}{ Drug-site II $^{d}$} & \multirow{2}{*}{$\frac{\text { Drug-site }^{b}}{166}$} & \multicolumn{2}{|c|}{ Drug-site II $^{c, d}$} \\
\hline & 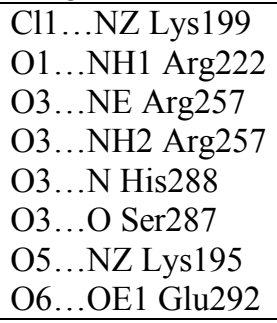 & $\begin{array}{l}2.46 \\
3.21 \\
3.21 \\
2.06 \\
2.96 \\
2.16 \\
3.28 \\
3.26 \\
\end{array}$ & 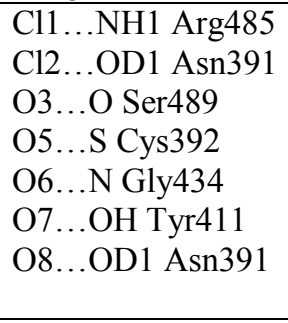 & $\begin{array}{l}3.13 \\
2.08 \\
2.68 \\
3.06 \\
2.95 \\
3.03 \\
2.97\end{array}$ & 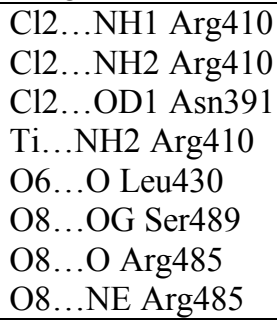 & $\begin{array}{l}2.94 \\
2.18 \\
2.37 \\
3.14 \\
2.86 \\
2.95 \\
2.77 \\
3.22 \\
\end{array}$ & & 126 & 126 \\
\hline $\mathbf{5 b}$ & $\begin{array}{l}\text { Cl1...NZ Lys199 } \\
\text { C12...NZ Lys199 } \\
\text { N4...O Glu292 }\end{array}$ & $\begin{array}{l}2.53 \\
2.48 \\
2.59\end{array}$ & $\begin{array}{l}\text { C11...OH Tyr411 } \\
\text { N2 ...NE Arg485 } \\
\text { N2...NH2 Arg485 } \\
\text { N2...OE1 Glu450 } \\
\text { N3 ...OE1 Gln390 }\end{array}$ & $\begin{array}{l}3.16 \\
3.09 \\
3.30 \\
3.15 \\
2.66 \\
\end{array}$ & 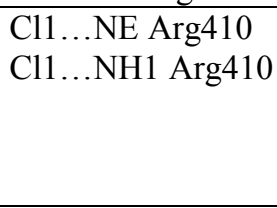 & $\begin{array}{l}3.26 \\
2.37\end{array}$ & 143 & 113 & 49 \\
\hline $5 c$ & $\begin{array}{l}\text { Ti...NH1 Arg222 } \\
\text { O1...O Arg257 }\end{array}$ & $\begin{array}{l}3.02 \\
2.69\end{array}$ & 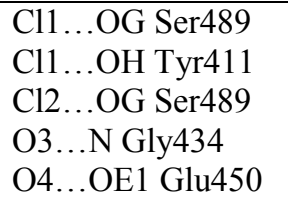 & $\begin{array}{l}3.09 \\
3.15 \\
3.30 \\
3.22 \\
2.39\end{array}$ & $\begin{array}{l}\text { C11.... NZ Lys414 } \\
\text { C11...O Ser489 } \\
\text { C12... N Ser489 } \\
\text { O4...OH Tyr411 }\end{array}$ & $\begin{array}{l}2.85 \\
2.65 \\
3.22 \\
3.14\end{array}$ & 111 & 116 & 88 \\
\hline
\end{tabular}

${ }^{a}$ The potential hydrogen bonds were assigned if the distance between two electronegative atoms was $<3.3 \AA$. The van der Waals interactions were assigned where the separation between non-bonded hydrogen atoms was $<4 \AA$ 
${ }^{b}$ known binding site for warfarin

${ }^{c}$ known binding site for diazepam

${ }^{d}$ known binding site for ibuprofen 


\section{Table 3}

\begin{tabular}{|c|c|c|c|c|c|c|c|c|c|c|c|}
\hline $\mathrm{Cpd}$ & \multicolumn{2}{|c|}{ H-bonds with distances $(\AA)^{a}$} & \multirow{2}{*}{$\begin{array}{c}\text { Number } \\
\text { of vdW }\end{array}$} & \multirow{2}{*}{$\begin{array}{r}\text { Cpd } \\
\mathbf{1 b}\end{array}$} & \multicolumn{2}{|c|}{ H-bonds with distances $(\AA)$} & \multirow{2}{*}{$\begin{array}{c}\text { Number } \\
\text { of vdW }\end{array}$} & \multirow{2}{*}{$\begin{array}{r}\text { Cpd } \\
\mathbf{1 c}\end{array}$} & \multicolumn{2}{|c|}{ H-bonds with distances $(\AA)$} & \multirow{2}{*}{$\begin{array}{c}\begin{array}{c}\text { Number } \\
\text { of vdW }\end{array} \\
83\end{array}$} \\
\hline $\mathbf{1 a}$ & 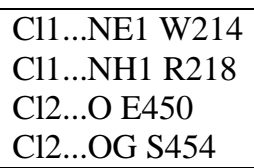 & $\begin{array}{c}2.98 \\
3.18 \\
3.07 \\
2.93\end{array}$ & & & $\begin{array}{l}\text { O1... OD1 D451 } \\
\text { O2...NE R485 }\end{array}$ & $\begin{array}{l}3.18 \\
3.00\end{array}$ & & & $\begin{array}{l}\text { O1...OD1 D451 } \\
\text { O2...NZ K199 }\end{array}$ & $\begin{array}{l}2.91 \\
2.93\end{array}$ & \\
\hline 1d & 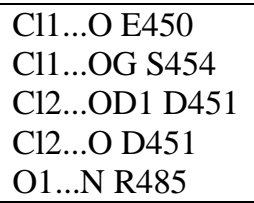 & $\begin{array}{l}3.06 \\
2.89 \\
2.29 \\
2.97 \\
3.07\end{array}$ & 80 & & & & & & & & \\
\hline $2 \mathbf{a}$ & $\begin{array}{l}\mathrm{Cl} 2 \ldots \mathrm{NE} 1 \mathrm{~W} 214 \\
\mathrm{O} 1 \ldots \mathrm{NE} 1 \mathrm{~W} 214 \\
\mathrm{O} 1 \ldots \mathrm{OE} 2 \mathrm{E} 450\end{array}$ & $\begin{array}{l}2.64 \\
3.16 \\
3.18\end{array}$ & 64 & $2 b$ & S2...O L481 & 2.63 & 57 & $2 c$ & Cl1...OG S454 & 3.16 & 63 \\
\hline $3 \mathbf{a}$ & $\begin{array}{l}\text { C11...NZ K199 } \\
\text { C12...NH1 R218 } \\
\text { N3...NE1 W214 } \\
\text { N6...NZ K199 } \\
\text { O4...NZ K199 }\end{array}$ & $\begin{array}{l}2.23 \\
2.98 \\
2.90 \\
3.04 \\
3.13\end{array}$ & 82 & $\mathbf{3 b}$ & $\begin{array}{l}\text { Cl1...NH1 R218 } \\
\text { C11...NH2 R218 } \\
\text { N6...NE1 W214 }\end{array}$ & $\begin{array}{c}2.50 \\
2.87 \\
2.93\end{array}$ & 90 & $3 c$ & 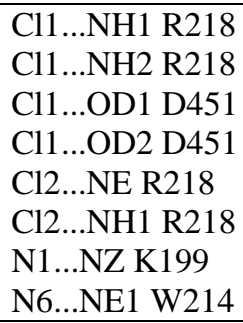 & $\begin{array}{l}3.20 \\
2.58 \\
2.89 \\
2.92 \\
3.01 \\
3.02 \\
2.90 \\
2.75\end{array}$ & 74 \\
\hline $4 \mathbf{a}$ & $\begin{array}{l}\text { Cl1...NE1 W214 } \\
\text { Cl2...NE1 W214 } \\
\text { O2...OG S454 }\end{array}$ & $\begin{array}{l}2.83 \\
3.86 \\
2.98\end{array}$ & 80 & $4 b$ & $\begin{array}{l}\mathrm{Cl1} \ldots \mathrm{OD} 1 \mathrm{D} 451 \\
\mathrm{C} 12 \ldots \mathrm{O} \text { D451 } \\
\mathrm{Cl} 2 \ldots \mathrm{OD} 1 \mathrm{D} 451 \\
\mathrm{Cl} 2 \ldots \mathrm{OG} \mathrm{S} 454\end{array}$ & $\begin{array}{l}2.94 \\
2.78 \\
3.27 \\
2.50\end{array}$ & 84 & $4 c$ & $\begin{array}{l}\text { Ti...NE1 W214 } \\
\text { N4...OG S454 }\end{array}$ & $\begin{array}{l}3.28 \\
3.04\end{array}$ & 99 \\
\hline $5 \mathbf{a}$ & $\begin{array}{l}\mathrm{Cl2} \ldots \mathrm{OG} \mathrm{S} 454 \\
\mathrm{O} 5 \ldots \mathrm{OD} 2 \mathrm{D} 451\end{array}$ & $\begin{array}{l}2.38 \\
2.59\end{array}$ & 140 & $5 \mathbf{b}$ & $\begin{array}{l}\text { Cl1...OG S454 } \\
\mathrm{Cl} 2 \ldots \text { OD1 D451 }\end{array}$ & $\begin{array}{l}2.18 \\
2.04\end{array}$ & 103 & $5 c$ & $\begin{array}{l}\text { Cl1...OG S454 } \\
\text { Cl1...O D451 } \\
\text { C12...OD1 D451 }\end{array}$ & $\begin{array}{l}2.38 \\
2.76 \\
2.58\end{array}$ & 99 \\
\hline
\end{tabular}

${ }^{a}$ The potential hydrogen bonds were assigned if the distance between two electronegative atoms was $<3.3 \AA$. The van der Waals interactions were assigned where the separation between non-bonded hydrogen atoms was $<4 \AA$. 
Table 1 Structures of the titanocenes derivatives (1a-d, 2a-c, 3a-c, 4a-c, 5a-c) in the dataset with their corresponding $\mathrm{IC}_{5 \mathrm{o}}$ values.

Table 2 Summary of the polar contacts and vdW interactions between the titanocene derivatives (1a-d, 2a-c, 3a-c. 4a-c, 5a-c) and the known drug binding sites of HSA (2BXD, 2BXF, 2BXG).

Table 3 Summary of the polar contacts and vdW interactions between the titanocene derivatives (1a-d, ${ }_{10}$ 2a-c, 3a-c. 4a-c, 5a-c) and HSA (1E7E) based on automated docking, where a new potential binding site has been postulated. 
Fig. 1 Structures of Cis-platin and titanocene dichloride.

Fig. 2 Representative examples of the substituted titanocene dichloride derivatives, a) ionic titanocenes, b) benzyl titanocene (Titanocene

$\left.{ }_{5} \mathrm{Y}\right)$ derived from fulvene.

Fig. 3 Cartoon diagram of the crystal structure of human serum albumin complexed with capric acid (PDBid 1E7E) showing the three domains colour coded and labelled I - III (each with two subdomains A and B), the bound fatty acids (FA) in magenta sticks, sties labelled 1-9, and the two drug${ }_{10}$ binding sites, drug site I and drug site II, located in the sub-domains IIA and IIIA, respectively.

Fig. 4 Docking results for the titanocene derivatives a) $\mathbf{1 b}$ at the warfarin binding site of HSA (PDB code, 2BXD), b) $\mathbf{1 b}$ at the diazepam binding site of HSA (PDB code, 2BXF), c) 3c at the warfarin binding site of HSA (PDB code, 2BXD), d) 3c at diazepam binding site of HSA (PDB code, 2BXF), e) ${ }_{5} \mathbf{5} \mathbf{c}$ at the warfarin binding site of HSA (PDB code, 2BXD), and f) $\mathbf{5 c}$ at the diazepam binding site of 2BXF). H-bonds (depicted by dashed lines) are shown between the titanocene ligand and each of the binding site residues of HSA with the bond length given in angstroms $(\AA)$. The ligand and binding site residues, in each case, are shown as pink and cyan sticks for the carbon atoms, respectively.

${ }_{20}$ Fig. 5 Docking result for $\mathbf{1 b}$ into fatty acid site 5 (FA5) of 1E7E showing exposure of titanocene. 
Fig.1<smiles>N[P+](N)(Cl)Cl</smiles>

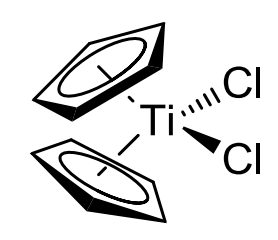

Cis-platin Titanocene dichloride

Fig.2

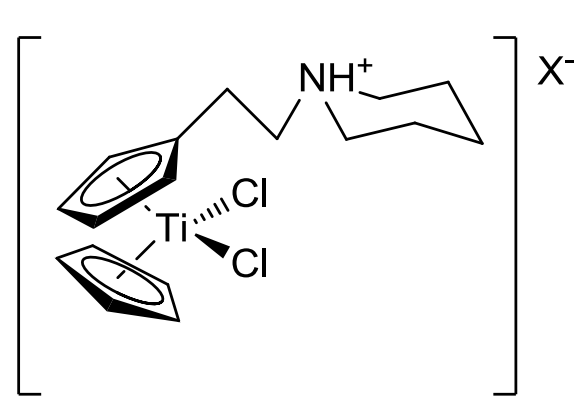

a

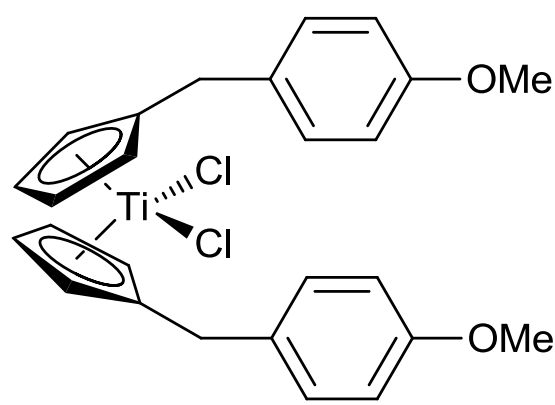

b
Field Code Changed 
Fig.3

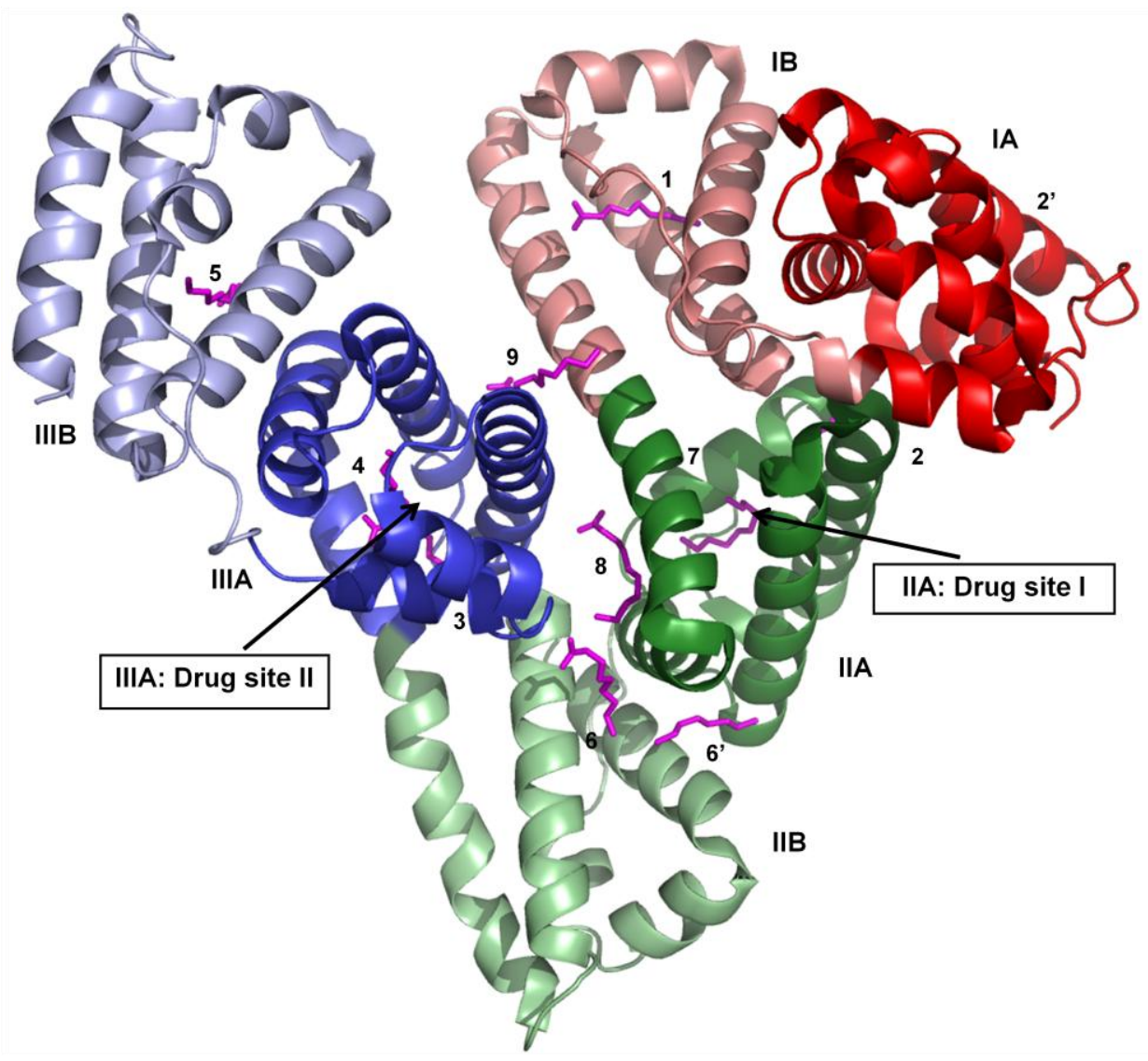


Fig. 4

a

b
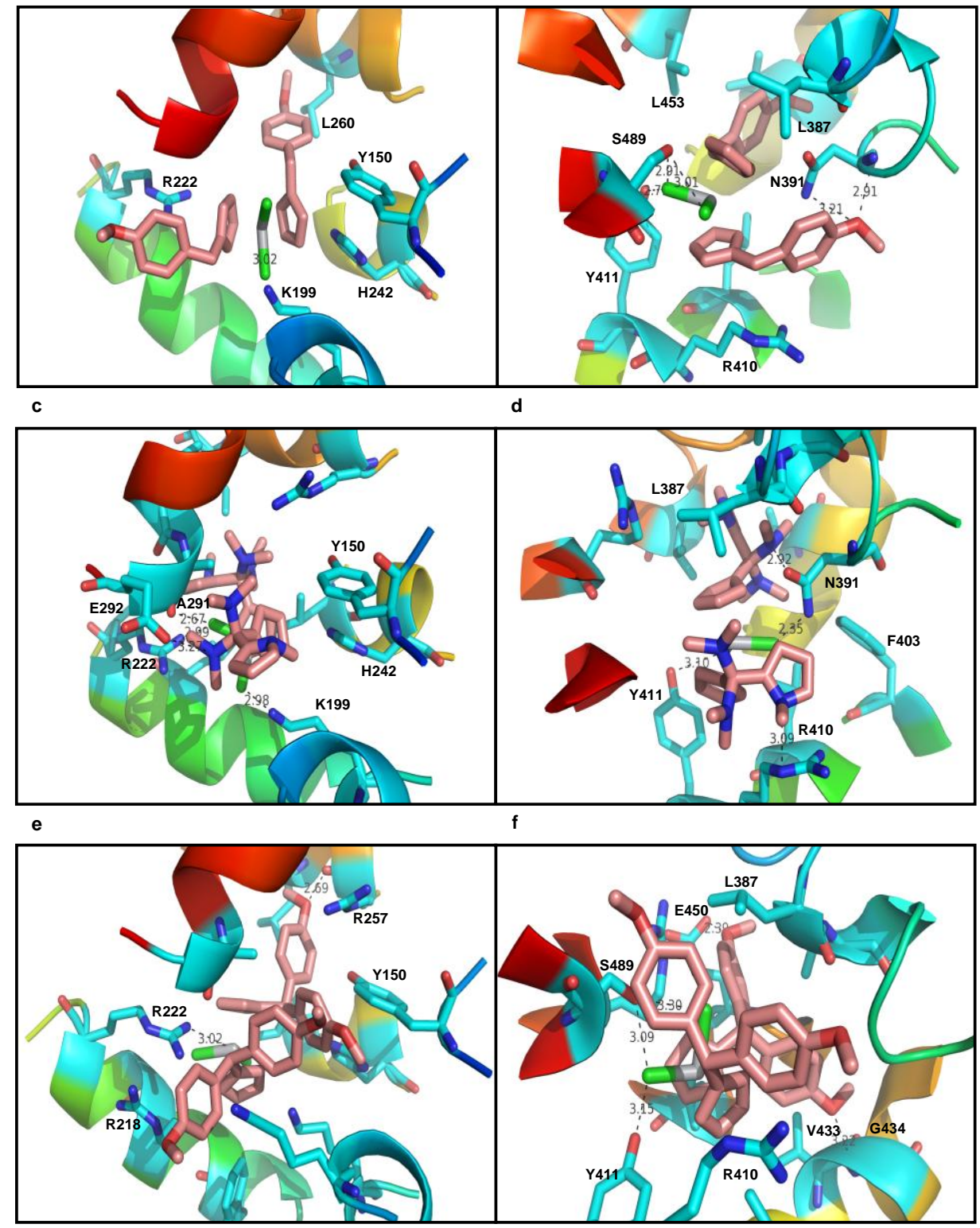
Fig. 5

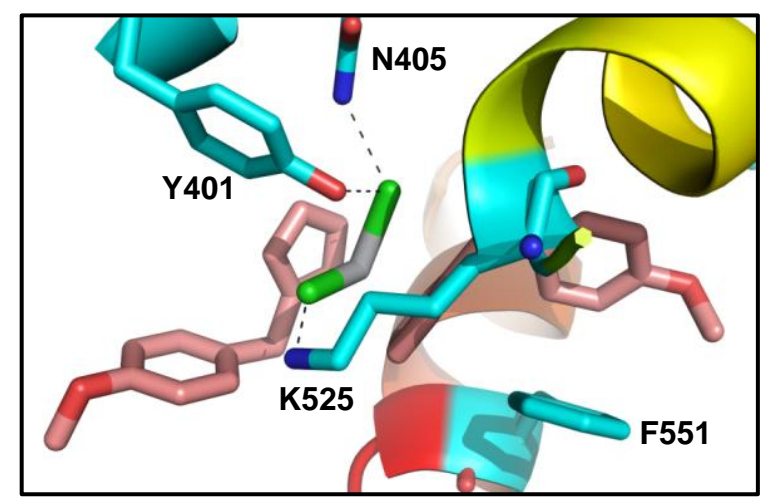




\section{Graphic contents entry}

\section{Figure}

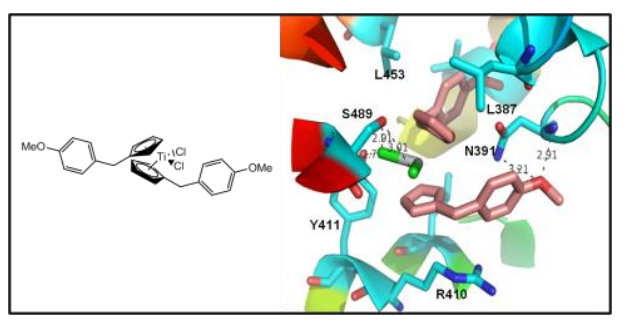

Text

10 A molecular docking study of novel titanocene derivatives to human serum album reveals potential modes of binding to the known drug binding sites and highlights a potential new binding site for these derivatives. 